\title{
Presence of Epstein-Barr virus latency type III at the single cell level in post-transplantation lymphoproliferative disorders and AIDS related lymphomas
}

Antoinette A T P Brink, Danny F Dukers, Adriaan J C van den Brule, Joost J Oudejans, Jaap M Middeldorp, Chris J L M Meijer, Mehdi Jiwa

\begin{abstract}
Aims-To investigate the expression pattern of Epstein-Barr virus (EBV) latent genes at the single cell level in posttransplantation lymphoproliferative disorders and acquired immunodefiency syndrome (AIDS) related lymphomas, in relation to cellular morphology.

try in a subpopulation of tumour cells using sensitive monoclonal antibodies $\mathbf{R 3}$ and 3E9. Our data suggest that EBV infected tumour cells in these lymphomas undergo gradual changes in the expression of EBV latent genes, and that these changes are associated with changes in cellular morphology.
\end{abstract}

Methods-Nine post-transplantation lymphoproliferative disorders and three AIDS related lymphomas were subjected to immunohistochemistry using monoclonal antibodies specific for EBV nuclear antigen 1 (EBNA1) (2H4), EBNA2 (PE2 and the new rat anti-EBNA2 monoclonal antibodies 1E6, R3, and 3E9), and LMP1 (CS1-4 and S12). Double staining was performed combining R3 or 3E9 with S12. Results-R3 and 3E9 anti-EBNA2 monoclonal antibodies were more sensitive than PE2, enabling the detection of more EBNA2 positive lymphoma cells. Both in post-transplantation lymphoproliferative disorders and AIDS related lymphomas, different expression patterns were detected at the single cell level. Smaller neoplastic cells were positive for EBNA2 but negative for LMP1. Larger and more blastic neoplastic cells, sometimes resembling Reed-Sternberg cells, were LMP1 positive but EBNA2 negative (EBV latency type II). Morphologically intermediate neoplastic cells coexpressing EBNA2 and LMP1 (EBV latency type III), were detected using $R 3$ and $3 E 9$, and formed a considerable part of the neoplastic population in four of nine post-transplantation lymphoproliferative disorders and two of three AIDS related lymphomas. All samples contained a subpopulation of small tumour cells positive exclusively for Epstein-Barr early RNA and EBNA1. The relation between cellular morphology and EBV expression patterns in this study was less pronounced in AIDS related lymphomas than in post-transplantation lymphoproliferative disorders, because the AIDS related lymphomas were less polymorphic than the post-transplantation lymphoproliferative disorders.

Conclusions-In post-transplantation lymphoproliferative disorders and AIDS related lymphomas, EBV latency type III can be detected by immunohistochemis-
(F Clin Pathol 1997;50:911-918)

Keywords: Epstein-Barr virus; lymphoma; immunocompromised host; immunohistochemistry; AIDS

Epstein-Barr virus (EBV) is the causative agent of infectious mononucleosis. ${ }^{1}$ In vitro, EBV can transform B lymphocytes, resulting in lymphoblastoid cell lines (LCLs). Moreover, the virus exhibits a strong association with endemic Burkitt's lymphoma, ${ }^{2}$ nasopharyngeal carcinoma, Hodgkin's disease, ${ }^{3}$ nasal $T$ nonHodgkin's lymphoma ${ }^{4}{ }^{4}$ and natural killer (NK) cell lymphoma ${ }^{6}$ in immunocompetent patients. EBV is also associated with lymphomas of immunocompromised patients, ${ }^{7}$ such as acquired immunodefiency syndrome (AIDS) related lymphomas and post-transplantation lymphoproliferative disorders. EBV is thought to contribute to malignant transformation in all of these these disorders. ${ }^{3}$ In LCLs and EBV positive malignancies, the virus is present latently and is transcriptionally active. To date, 12 gene products have been detected in association with EBV latency. However, in EBV positive lymphomas in immunocompetent patients, usually the EBV gene expression pattern is restricted. A limited expression pattern termed latency type $\mathrm{I}^{8}$ is detected in Burkitt's lymphoma. This implies expression of the transcription factor EBV nuclear antigen 1 (EBNA1), the small non-coding RNAs EBER1 and 2 , and the BARF0 transcripts. ${ }^{9}$ In EBV positive Hodkin's disease and nasal $T$ nonHodgkin's lymphomas in immunocompetent patients, the Epstein-Barr early RNAs (EBERs), EBNA1, and BARF0 are expressed together with the latent membrane proteins LMP1, LMP2a, and LMP2 $\mathrm{b}^{10}{ }^{11}$ (latency type II). ${ }^{8}$ In LCLs, the expression pattern is extended to EBNA2, EBNA3a, EBNA3b, EBNA3c, and EBNA4 transcripts. ${ }^{12}$ This extensive expression pattern is termed latency type III. ${ }^{8}$

In vivo, latency type III-like expression patterns have been found in posttransplantation lymphoproliferative disorders 
using non-morphological methods such as western blotting ${ }^{13}$ and reverse transcriptase polymerase chain reaction (RT-PCR) ${ }^{14}$ Using immunohistochemical staining specific for EBNA2 and LMP1 (monoclonal antibodies PE2 and monoclonal antibody cocktail CS1-4, respectively), Rea et $a l^{1516}$ reported either latency type I, II, or III in different posttransplantation lymphoproliferative disorder biopsies depending on whether the phenotype was monomorphic or polymorphic. However, the detection of latency type II instead of type III in some polymorphic post-transplantation lymphoproliferative disorders in the latter study is attributed partly to the low sensitivity of the PE2 anti-EBNA2 monoclonal antibody. This low sensitivity may also have prevented Oudejans et al from detecting latency type III at the single cell level in post-transplantation lymphoproliferative disorders using immunohistochemical double staining specific for EBNA2 (monoclonal antibody PE2) and LMP1 (monoclonal antibody S12), ${ }^{17}$ resulting in the conclusion that the latency type III pattern in post-transplantation lymphoproliferative disorders (as found by western blotting) was the result of at least three different subpopulations of lymphoma cells.

EBV positive AIDS related lymphomas share some common features with EBV positive post-transplantation lymphoproliferative disorders. Both lymphoma subtypes arise in patients with an impaired immune response. Moreover, the same EBV proteins have been detected in both disorders. ${ }^{15} 1819$ In addition, similar morphological features have been reported in both lymphoma types, for instance the presence of Reed-Sternberg-like blasts. ${ }^{18} 19$ It was demonstrated that polymorphic AIDS related lymphomas harbour more LMP1 positive lymphoma cells than monomorphic AIDS related lymphomas, and that LMP1 positive AIDS related lymphoma cells are usually of the Reed-Sternberg-like type ${ }^{1820}$ as in posttransplantation lymphoproliferative disorders. ${ }^{17}$ Coexpression of LMP1 and other EBV proteins at the single cell level has not been studied before in AIDS related lymphomas.

There are several indications for the presence of latency type III at the single cell level in both types of lymphoma. First, EBNA2 is known to be a transactivator of other EBV genes including LMP1. ${ }^{21}$ Therefore, it is likely

Table 1 Characteristics of clinical material

\begin{tabular}{llll}
\hline Case & $\begin{array}{l}\text { Cause of immune } \\
\text { suppression }\end{array}$ & Biopsy site & Histology \\
\hline 1 & Allogeneic BMT & Lymph node & Polymorphic, large cell B \\
2 & Allogeneic BMT & Lymph node & Polymorphic, large cell B \\
3 & Allogeneic BMT & Lymph node & Polymorphic, large cell B \\
4 & Allogeneic BMT & Lymph node & Polymorphic, large cell B \\
5 & Allogeneic BMT & Lymph node & Immunoblastic \\
6 & Allogeneic BMT & Lymph node & Polymorphic, large cell B \\
7 & Allogeneic BMT & Lymph node & Polymorphic centroblastic \\
8 & Kidney transplantation & Kidney & Polymorphic centroblastic \\
9 & Kidney transplantation & Lymph node & Immunoblastic \\
10 & AIDS & Lymph node & Large cell B \\
11 & AIDS & CNS & Polymorphic centroblastic \\
12 & AIDS & Lymph node & Polymorphic \\
13 & Not applicable & Lymph node neck & Not applicable \\
\hline
\end{tabular}

Post-transplantation lymphoproliferative disorder case 1 proved to be monoclonal, case 3 oligoclonal, and case 4 monocolonal as determined by Southern blotting analysis. that at certain stages of lymphomagenesis these gene products are present in lymphoma cells simultaneously, especially in lymphomas of immuncompromised patients where EBNA2 expressing-and thus immunogenic-lymphoma cells are not eradicated because of the impaired immune response. Second, Kerr et $a l^{22}$ showed that, in vitro, EBV infected cells can switch from a latency type I to latency type III and, subsequently, back to latency type I or II; hence transition from one EBV latency pattern to another is possible. Also, such transitions may be reflected by the different cellular phenotypes observed within individual posttransplantation lymphoproliferative disorder biopsies. ${ }^{15} 162324$ However, proper diagnostic tools are indispensable because some cells might express low amounts of protein. Recently, a new set of highly sensitive antiEBNA2 monoclonal antibodies was developed.$^{25}$ Using these antibodies in combination with an anti-LMP1 monoclonal antibody we investigated expression of EBNA2 and LMP1, along with EBNA1, and EBER1 and 2 at the single cell level in relation to cellular morphology in several lymphomas of immunocompromised patients with post-transplantation lymphoproliferative disorders and AIDS related lymphomas.

\section{Methods}

CELL LINES

The EBV positive cell lines JY, Raji, X507, JC5, HH514.C16 (infected with an EBNA2 deleted EBV strain), and the EBV negative cell line Ramos were cultured at $37^{\circ} \mathrm{C}$ in RPMI 1640 containing $10 \%$ fetal calf serum (FCS) in a humidified atmosphere containing $5 \% \mathrm{CO}_{2}$.

Cell suspensions were embedded in cellulose (cytoblock kit; Shandon, Pittsburgh, Pennsylvania, USA), fixed in buffered formalin, and embedded in paraffin. Sections of $4 \mu \mathrm{m}$ were cut for immunohistochemistry.

CLINICAL MATERIAL

Four cases of post-transplantation lymphoproliferative disorder were obtained from the department of pathology of the Academical Hospital, Leiden. Material from five posttransplantation lymphoproliferative disorders, three AIDS related lymphomas, and one infectious mononucleosis case was obtained from the Academical Hospital of Utrecht. Characteristics of these samples are summarised in table 1 . The site of origin of these tumours was difficult to determine as most of them were generalised at the time of diagnosis. Instead, the site of biopsy is mentioned when known. To verify EBV association, EBER RNA in situ hybridisation was performed on $4 \mu \mathrm{m}$ paraffin sections as described previously. ${ }^{26}$ As a positive control for EBER RNA in situ hybridisation, an EBV positive case of Hodgkin's disease was used. Hybridisation of all samples with the EBER sense probe served as a negative control; moreover, the non-neoplastic infiltrate in the EBV positive Hodgkin's disease case was always negative using EBER RNA in situ hybridisation. Immunohistochemistry was also performed on $4 \mu \mathrm{m}$ sections. 


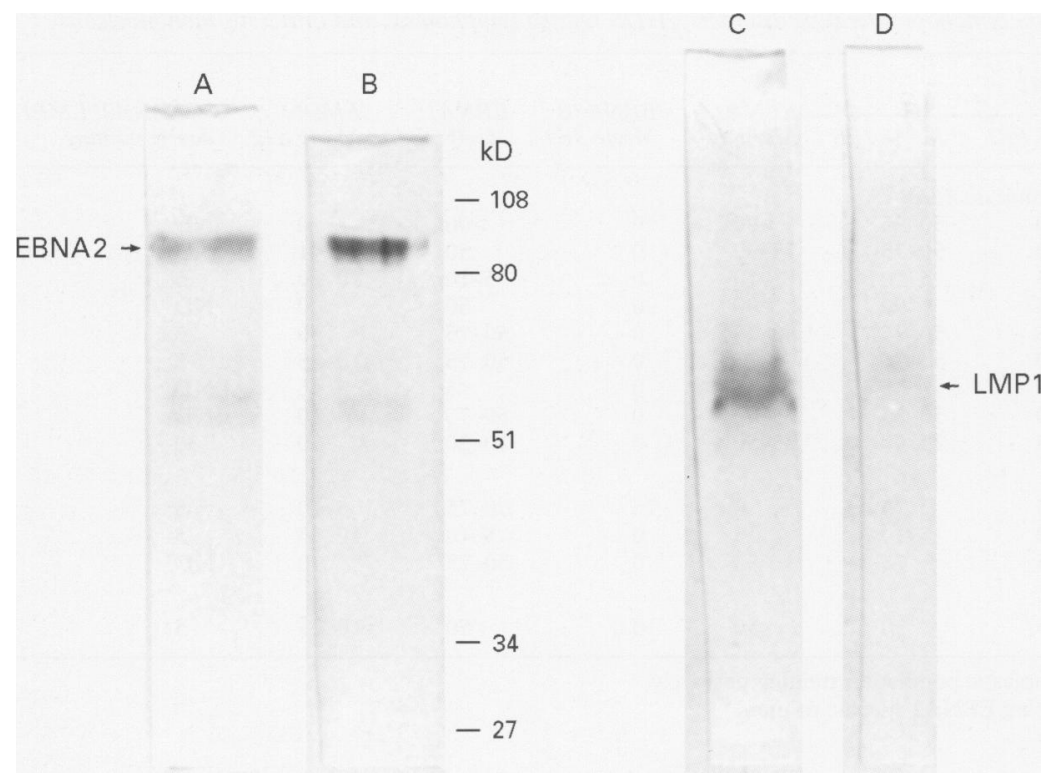

Figure 1 Western blotting analysis to compare sensitivities of the anti-EBNA2 monoclonal antibodies $R 3(A)$ and PE2 $(B)$, and the anti-LMP1 monoclonal antibodies $S 12(C)$ and $C S 1-4$ (D). R3 and PE2 detect the $88 \mathrm{kDa} E B N A 2 A$ protein with comparable efficiency in western blotting. The $66 \mathrm{kDa} L M P 1$ protein is detected more efficiently by $S 12$ than by $C S 1-4$.

Of the EBV positive lymphomas, eight posttransplantation lymphoproliferative disorders were shown to harbour EBV type 1 using DNA PCR with EBNA2 specific primers as described previously ${ }^{27}$ (one sample was not tested owing to lack of material). Two AIDS related lymphomas contained EBV type 1, and one AIDS related lymphoma contained EBV type 2. As shown by DNA PCR, the EBV positive cell lines harboured EBV type 1 with the exception of JC5, which contained EBV type 2.

Furthermore, all lymphomas and EBV positive cell lines were shown to express EBNA1, EBNA2, and LMP1 at the mRNA level using RT-PCR as described previously, ${ }^{14}$ with the exception of the HH514C16 cell line, which did not express EBNA2 owing to a genomic deletion.

MONOCLONAL ANTIBODIES

To enable efficient detection of low concentrations of EBNA2 protein, we used several highly sensitive anti-EBNA2 rat monoclonal antibodies, which have been developed recently (R3, 3E9, and 1E6, kindly provided by Dr E Krem-

Table 2 Immunohistochemical analysis of EBNA2 expression in cell lines comparing different anti-EBNA2 monoclonal antibodies

\begin{tabular}{|c|c|c|c|c|c|c|}
\hline \multirow[b]{2}{*}{ Cell line } & \multirow[b]{2}{*}{$E B V$ type } & \multicolumn{2}{|l|}{$E B N A 2$} & \multirow{2}{*}{$\begin{array}{l}E B N A 2 A \\
M o A b R 3\end{array}$} & \multirow{2}{*}{$\begin{array}{l}E B N A 2 B \\
\text { Mo } A b 3 E 9\end{array}$} & \multirow{2}{*}{$\begin{array}{l}\% \text { EBNA2/ } \\
\text { LMP1 double } \\
\text { staining }\end{array}$} \\
\hline & & $M o A b$ PE2 & $M o A b 1 E 6$ & & & \\
\hline Raji & 1 & 90 & 95 & $>95$ & 0 & 90 \\
\hline $\mathrm{JY}$ & 1 & 90 & 95 & $>95$ & 0 & 90 \\
\hline$\times 50.7$ & 1 & 90 & 95 & $>95$ & 0 & 90 \\
\hline JC5 & 2 & 90 & 95 & 0 & $>95$ & 90 \\
\hline HH514C16 & $-t$ & 0 & 0 & 0 & 0 & 0 \\
\hline Ramos & - & 0 & 0 & 0 & 0 & 0 \\
\hline
\end{tabular}

Values are percentage of cultured cells staining positively.

In all cell lines, a proportion of $90 \%$ stained positive for EBNA1 and LMP1 using immunohistochemistry, with the exception of the EBV negative cell line Ramos (negative for both EBNA1 and LMP1) and the HH514C16 cell line ( $<5 \%$ LMP1 positive).

${ }^{\star}$ As determined by DNA-PCR using EBNA2 specific primers. ${ }^{27}$

tIn the HH514C16 cell line, no EBV typing with EBNA2 specific PCR was possible because of a genomic deletion in the EBNA2 region. mer, Munich, Germany). R3 recognises epitopes specific for EBV type 1, 3E9 recognises EBV type 2 encoded EBNA2, and 1E6 recognises both. ${ }^{25}$ As a reference for sensitivity the anti-EBNA2 monoclonal antibody PE2 (Dako, Glostrup, Denmark) was used. As a reference for the specificity of these monoclonal antibodies for the two EBV types we compared immunohistochemistry with DNA PCR. For detection of LMP1, both mouse anti-LMP1 monoclonal antibody $\mathrm{S} 12$ (Organon Teknika, Boxtel, Netherlands) and the mixture of four anti-LMP1 antibodies CS1-4 (Dako) were used. EBNA1 protein was detected using the 2B4 monoclonal antibody ${ }^{28}$ (kindly provided by Dr E Kremmer, Munich, Germany).

WESTERN BLOT ANALYSIS OF EBV PROTEINS Western blots were prepared from SF9 insect cells, transfected with EBNA2A or LMP1 recombinant baculovirus (kindly provided by Dr P Meij, University Hospital Vrije Universiteit, Amsterdam, Netherlands). Each lane contained the crude lysate of $10^{5}$ SF9 cells. Blots were incubated for one hour in blocking buffer ( $5 \% \mathrm{FCS}, 5 \%$ milk powder in phosphate buffered saline (PBS)) followed by one hour incubation with primary antibodies diluted $1 / 100$ in blocking buffer. After washing three times for five minutes in PBS $/ 0.05 \%$ Tween 20 , blots were incubated for one hour with secondary antibodies-rabbit antimouse horseradish peroxidase (HRP) (Dako) and rabbit antirat HRP (Dako), both diluted 1/1000 in blocking buffer. The peroxidase was visualised for one hour using $0.05 \%$ naphtol $/ 0.01 \% \mathrm{H}_{2} \mathrm{O}_{2}$ in PBS.

IMMUNOHISTOCHEMISTRY OF EBV PROTEINS

Single staining

All immunohistochemistry was performed on formalin fixed, paraffin embedded material. Sections were deparaffinised with xylene and rehydrated; endogenous peroxidase was inactivated by incubation with $0.3 \% \mathrm{H}_{2} \mathrm{O}_{2}$ in methanol for 30 minutes. Antigens were retrieved by boiling the slides in $0.1 \mathrm{M}$ citrate buffer $\mathrm{pH} 6.0$ for 10 minutes. Slides were incubated with the primary antibody and subsequently with biotinylated secondary antibodies. A biotinylated rabbit antimouse antiserum (1/500; Dako) was used for detection of those primary antibodies raised in mice, whereas a biotinylated goat antirat antiserum (1/500; Jackson Immunoresearch, West Grove, Pennsylvania, USA) was used to detect primary antibodies raised in rats. Detection of antibody complexes was performed using an avidin-biotin-HRP complex (sABC; Dako). The peroxidase was visualised by incubation for three minutes in $0.4 \mathrm{mg} / \mathrm{ml}$ diaminobenzidine (DAB), $0.002 \% \mathrm{H}_{2} \mathrm{O}_{2}$ in $50 \mathrm{mM}$ Tris $\mathrm{HCl}, \mathrm{pH} 7.6$ (brown staining). To provide a negative control for the immunostaining, primary antibodies were substituted with PBS.

\section{Double staining}

Slides were pretreated as for single staining. Slides were incubated with R3 or 3E9 antiEBNA2 monoclonal antibodies followed by 
Table 3 Immunohistochemical analysis of EBNA1, EBNA2 (comparing different monoclonal antibodies), and LMP1 expression in post-transplantation lymphoproliferative disorders, AIDS related lymphomas, and infectious mononucleosis

\begin{tabular}{|c|c|c|c|c|c|c|c|c|}
\hline \multirow[b]{2}{*}{ Sample } & \multirow[b]{2}{*}{$E B V$ type * } & \multicolumn{2}{|l|}{$E B N A 2$} & \multirow{2}{*}{$\begin{array}{l}E B N A 2 A \\
M o A b R 3\end{array}$} & \multirow{2}{*}{$\begin{array}{l}E B N A 2 B \\
M o A b 3 E 9\end{array}$} & \multirow{2}{*}{$\begin{array}{l}E B N A 1 \\
M o A b 2 B 4\end{array}$} & \multirow{2}{*}{$\begin{array}{l}L M P 1 \\
M o A b S 12\end{array}$} & \multirow{2}{*}{$\begin{array}{l}\% \text { EBNA2/ LMP1 } \\
\text { double staining }\end{array}$} \\
\hline & & $M o A b$ PE2 & $M o A b 1 E 6$ & & & & & \\
\hline \multicolumn{9}{|c|}{ Post-transplantation lymphoproliferative disorders } \\
\hline 1 & ND & $25-50$ & $50-75$ & $>90$ & 0 & $>90$ & 0 & ND \\
\hline 2 & 1 & 50 & $50-75$ & $75-90$ & 0 & 50 & $<1$ & ND \\
\hline 3 & 1 & $<5$ & $5-10$ & 10 & 0 & $5-10$ & $10-20$ & 5 \\
\hline 4 & 1 & $50-75$ & 90 & $>90$ & 0 & 50 & 0 & ND \\
\hline 5 & 1 & $50-75$ & $50-75$ & $50-75$ & 0 & $50-75$ & 50 & 25 \\
\hline 6 & 1 & $25-50$ & $50-75$ & 75 & 0 & $50-75$ & $10-25$ & 5 \\
\hline 7 & 1 & $<5$ & $<5$ & $<5$ & 0 & $<5$ & $<5$ & ND \\
\hline 8 & 1 & $25-50$ & $50-75$ & $75-90$ & 0 & $50-75$ & 0 & ND \\
\hline 9 & 1 & $<5$ & $25-50$ & $25-50$ & 0 & $10-20$ & 50 & 30 \\
\hline \multicolumn{9}{|c|}{ AIDS related lymphomas } \\
\hline 10 & 2 & $50-75$ & 75 & 0 & 75 & $50-75$ & $5-10$ & 5 \\
\hline 11 & 1 & $5-10$ & $5-10$ & 25 & 0 & $5-10$ & $10-25$ & 5 \\
\hline 12 & 1 & 75 & 75 & 75 & 0 & $50-75$ & 0 & ND \\
\hline \multicolumn{9}{|c|}{ Infectious mononucleosis } \\
\hline 13 & ND & $10-25$ & 50 & 50 & 0 & 50 & $10-25$ & 5 \\
\hline
\end{tabular}

Values are percentage of total neoplastic population staining positively. ${ }^{\star}$ As determined by DNA PCR using EBNA2 specific primers. ${ }^{27}$ ND, not determined.

biotinylated goat antirat and SABC, and these complexes were visualised by incubation for 10 minutes in $0.2 \mathrm{mg} / \mathrm{ml} \mathrm{DAB}, 0.002 \% \mathrm{H}_{2} \mathrm{O}_{2}$ and $0.12 \% \mathrm{NiSO}_{4} /\left(\mathrm{NH}_{4}\right)_{2} \mathrm{SO}_{4}$ in $50 \mathrm{mM}$ Tris $\mathrm{HCl}$, $\mathrm{pH} 7.6$ (black staining). Remaining peroxidase was inactivated as described above and slides were fixed for 10 minutes using $4 \%$ paraformaldehyde in PBS. Slides were then incubated with S12 anti-LMP1 monoclonal antibody followed by biotinylated rabbit antimouse and sABC. This antibody complex was visualised by incubation for three minutes in $0.4 \mathrm{mg} / \mathrm{ml}$ $\mathrm{DAB}, 0.002 \% \mathrm{H}_{2} \mathrm{O}_{2}$ in $50 \mathrm{mM}$ Tris $\mathrm{HCl}$, pH 7.6 (brown staining).

\section{Results}

EVALUATION OF ANTI-EBNA2 MONOCLONAL ANTIBODIES

The anti-EBNA2 antibodies R3 and PE2 were compared for their sensitivities in western blot analysis (fig 1) and were found to be almost equally sensitive in the recognition of linear epitopes. However, when PE2 was compared with the new rat monoclonal antibodies in immunohistochemistry, clear differences in sensitivity were observed, which are summarised in tables 1 and 2. All three new monoclonals showed both a higher number of positive cells and higher staining intensities in cell lines, post-transplantation lymphoproliferative disorders, AIDS related lymphomas, and infectious mononucleosis (tables 2 and 3; figs 2 and 3). Using PE2 in immunohistochemistry on clinical material, EBNA2 was detected mainly in smaller tumour cells (fig 2A), whereas 1E6 and R3 also stained some larger, more blastic tumour cells (figs $2 \mathrm{~B}$ and $4 \mathrm{~A}$ ). The low sensitivity of PE2 may be because the epitope recognised by this antibody is concealed by formalin fixation of the tissue.

Specificities of the monoclonal antibodies for the EBV types 1 and 2 were determined in those cases where the EBV type had been determined previously using DNA PCR. Immunohistochemistry results correlated well with DNA PCR results: R3 recognised only EBV type 1 encoded EBNA2, whereas 3E9 recognised type 2 encoded EBNA2 exclusively, and $1 \mathrm{E} 6$ and PE2 recognised both (tables 2 and 3). Based on these results, R3 and 3E9 appeared to be most suitable for detection of EBNA2 protein.

EVALUATION OF ANTI-LMP1 MONOCLONAL ANTIBODIES

Sensitivities of the monoclonal anti-LMP1 antibody $\mathrm{S} 12$ and the monoclonal antibody
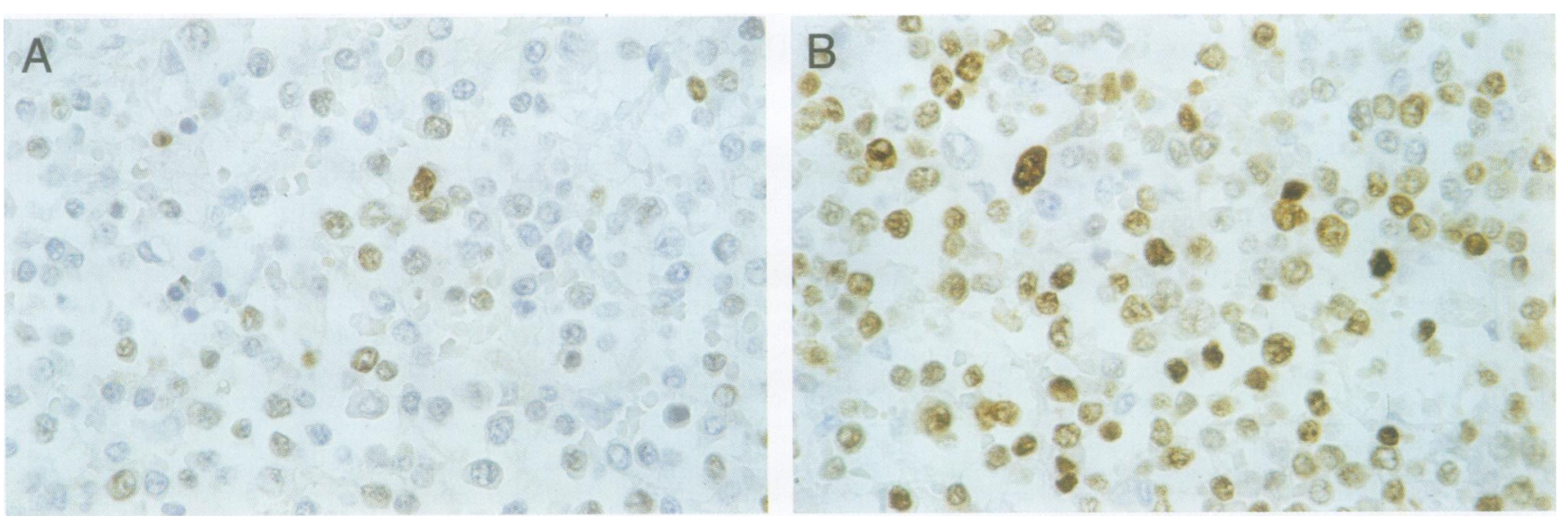

Figure 2 Immunohistochemical analysis of EBNA2 expression in post-transplantation lymphoproliferative disorder case 2, comparing the monoclonal antibodies PE2 and R3. (A) With PE2, $50 \%$ of the neoplastic population is EBNA2 positive. (B) With R3, $90 \%$ of the neoplastic population stains positively for EBNA2. The staining intensity obtained with $1 E 6$ and $R 3$ is stronger than that obtained with PE2. 

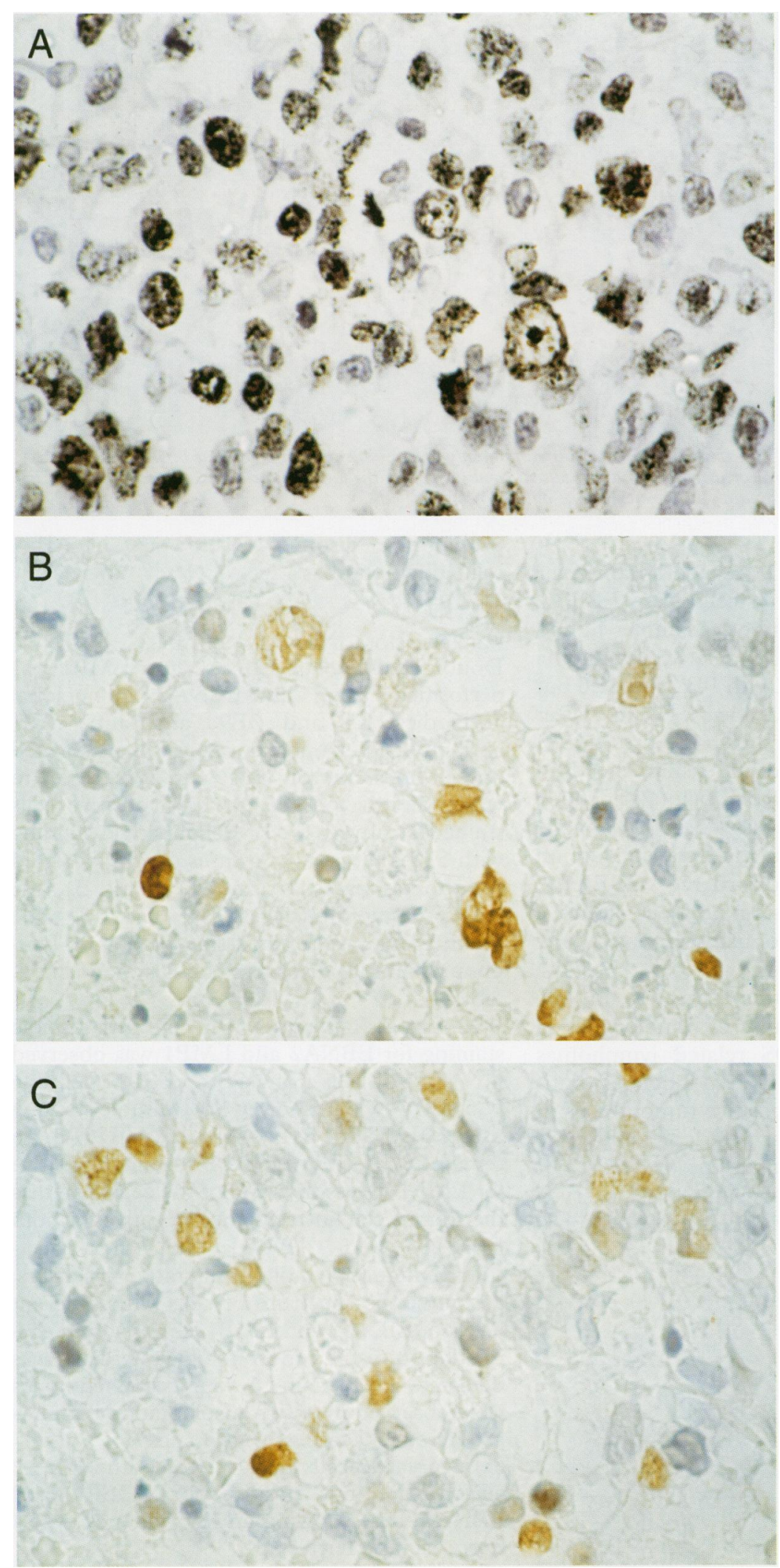

Figure 3 (A) EBER RNA in situ hybridisation analysis of post-transplantation lymphoproliferative disorder case 9. (B) EBNA1 and (C) EBNA2 immunohistochemical analysis of the same case. Both EBNA1 and EBNA2 are expressed in large and small neoplastic cells. for the immunohistochemical detection of LMP1 in cell lines and clinical material in the present study.

EXPRESSION OF EBV LATENT GENES IN CELL LINES AND CLINICAL MATERIAL

As previously shown by RT-PCR, all lymphomas and cell lines except HH514C16 (containing an EBV strain with an EBNA2 deletion) and Ramos (an EBV negative Burkitt's lymphoma cell line), expressed EBNA2 and LMP1 at the mRNA level. This is indicative of an EBV latency type III expression pattern. However, in immunohistochemical assays using the R3 and 3E9 anti-EBNA2 monoclonals and the S12 anti-LMP1 monoclonal antibody, differences between the in vitro and in vivo situations at the single cell level were observed.

\section{Cell lines}

EBNA1 was detected in $90 \%$ of cultured EBV positive cells. LMP1 was also detected in $90 \%$ of cultured cells, except in the cell line HH514C16 in which LMP1 was expressed in less than $5 \%$ of cells. Using the sensitive anti-EBNA2 monoclonal R3 (or 3E9 for cell line JC5), EBNA2 was detected in $>95 \%$ of cultured cells. EBNA2 was not detected in the cell lines HH514C16 (EBNA2 deficient) and Ramos (EBV negative) (table 2).

\section{Infectious mononucleosis}

The infectious mononucleosis case showed EBNA2 positivity in $50 \%$ of the EBV positive cells. Of the EBV positive cells, $10-25 \%$ were LMP1 positive; these were mainly large ReedSternberg-like blasts, which are often seen in infectious mononucleosis; EBNA1 protein was detected in $50 \%$ of the EBV positive cells, both in large blasts and in smaller cells.

Post-transplantation lymphoproliferative disorders In this disorder, numbers of EBNA2 positive cells varied from $5-90 \%$ of the neoplastic population using the R3 monoclonal. EBER1/2, EBNA1, and EBNA2 staining of successive slides revealed the presence, of a small population positive exclusively for EBER1/2 and EBNA1. EBNA1 was detected in both large and small neoplastic cells (fig 3). None of the post-transplantation lymphoproliferative disorders stained positive with the 3E9 monoclonal antibody, which is specific for EBV type 2 encoded EBNA2. This was in agreement with DNA PCR results, which had revealed the presence of EBV type 1 but not type 2 in all of the post-transplantation lymphoproliferative disorder biopsies.

Using the S12 anti-LMP1 monoclonal antibody, LMP1 expression could be detected only in the cytoplasm and membranes of large blastic, sometimes Reed-Sternberg-like tumour cells (fig 4B). In smaller tumour cells, LMP1 was not detected. Six out of nine posttransplantation lymphoproliferative disorders, and the infectious mononucleosis case stained positive for LMP1 (table 3). 


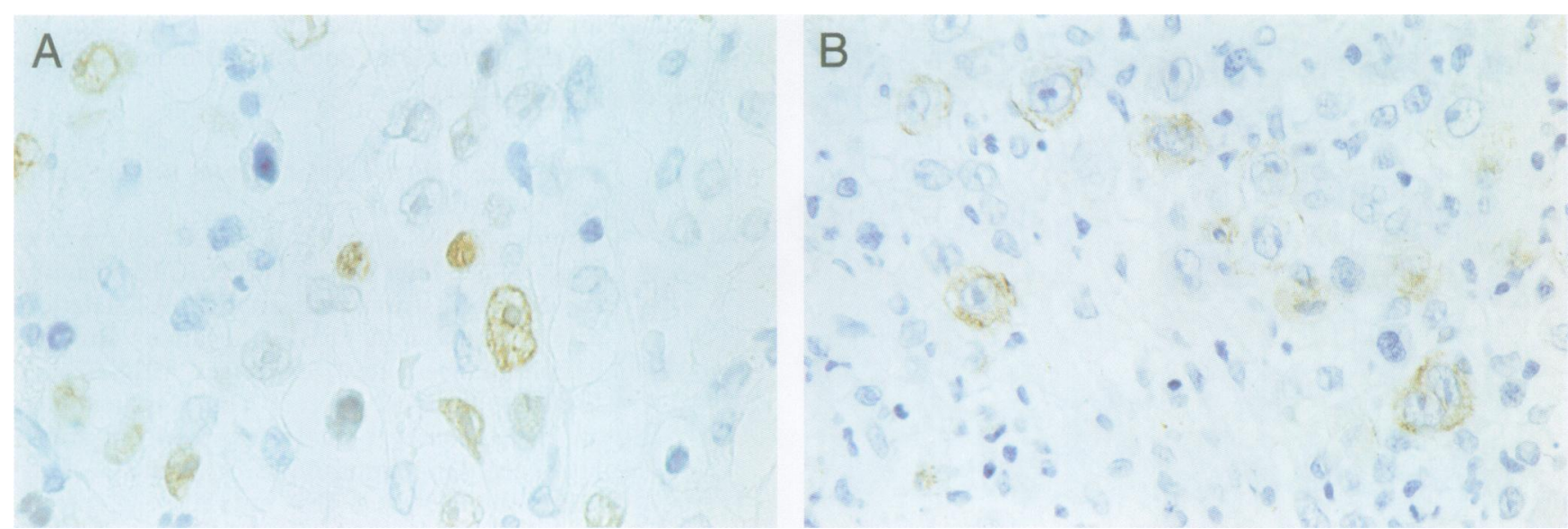

Figure 4 Immunohistochemical analysis of LMP1 and EBNA2 expression in post-transplantation lymphoproliferative disorder case 6. (A) EBNA2, as detected by the R3 monoclonal antibody, is expressed in smaller neoplastic cells and to a lesser extent in some of the larger, more anaplastic cells. (B) LMP1 protein, as detected by the $S 12$ monoclonal antibody, is detected mainly in the membranes of large neoplastic cells.

AIDS related lymphomas

In two of the three AIDS related lymphomas, $5-75 \%$ of the lymphoma cells were EBNA2 positive using the $\mathrm{R} 3$ antibody (samples 11 and 12, table 3). One AIDS related lymphoma sample showed staining with PE2 and 1E6 but not with R3 (sample 10, table 3). For this latter sample DNA PCR had shown the presence of EBV type 2 and, indeed, using the 3E9 antibody specific for EBV type 2 encoded EBNA2, staining was observed in $75 \%$ of the tumour cells. As in the post-transplantation lymphoproliferative disorder, EBER1/2, EBNA1, and EBNA2 staining of consecutive slides showed a small population positive only for EBER1/2 and EBNA1.

LMP1 expression was detected in the cytoplasm and membranes of tumour cells in two of the three AIDS related lymphomas using the S12 anti-LMP1 monoclonal antibody (table 3). LMP1 positive tumour cells in AIDS related lymphomas were larger and more blastic than LMP1 negative tumour cells, but clear Reed-Sternberg-like features, as observed in abundance in post-transplantation lympho-

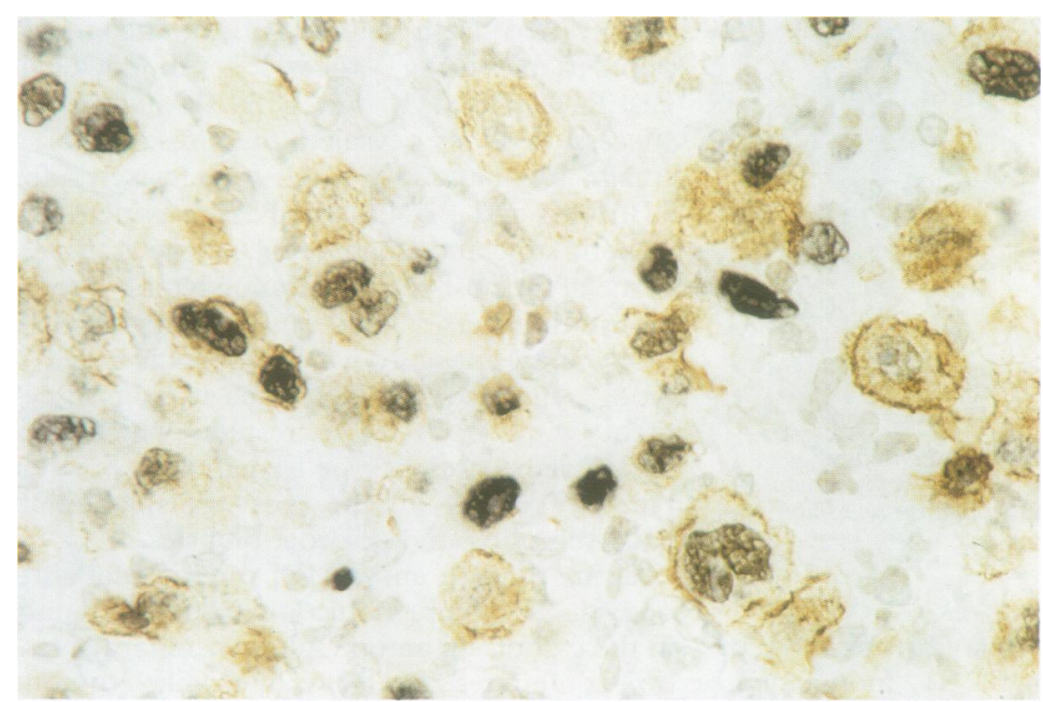

Figure 5 Double staining for EBNA2 (black) and LMP1 (brown) in post-transplantation lymphoproliferative disorder case 6. This staining shows a continuous spectrum of smaller tumour cells staining strongly for EBNA2, but staining relatively weakly for LMP1, via intermediate phenotypes to larger, more anaplastic tumour cells even resembling (mononuclear variants of) Reed-Sternberg cells, staining positively for LMP1, but negatively for EBNA2. proliferative disorders, were rare in AIDS related lymphomas.

\section{COEXPRESSION OF EBNA2 AND LMP1}

Double staining for EBNA2 and LMP1 was performed using anti-EBNA2 monoclonal antibodies R3 and 3E9, and anti-LMP1 antibody S12. Double staining was performed on cell lines, and on those clinical samples in which at least $5 \%$ of the EBV positive cells stained positively for LMP1 in single staining with S12; that is, in two cases of AIDS related lymphoma (cases 10 and 11 , table 3 ), the infectious mononucleosis case (case 13, table 3 ), and four cases of post-transplantation lymphoproliferative disorders (cases 3, 5, 6, and 9, table 3).

In the JY, Raji, and X50.7 cell lines, double staining for EBNA2 and LMP1 was observed in $\sim 90 \%$ of cells using R3 and S12. Cell line JC5 (EBV type 2) showed 90\% double staining using 3E9 and S12. Cell line HH514C16 remained EBNA2 negative but stained positive for LMP1 in less than $5 \%$ of the cells, whereas the Ramos cell line remained negative for both EBNA2 and LMP1. In the posttransplantation lymphoproliferative disorders, a continuous spectrum of cells with different levels of EBNA2 and LMP1 expression in correlation to distinct morphological features was detected. Four main tumour cell phenotypes were observed in post-transplantation lymphoproliferative disorders (figs 3 and 5):

(1) neoplastic cells negative for both EBNA2 and LMP1 but positive for EBER1 and EBNA1, thus showing an EBV latency type I expression pattern

(2) neoplastic cells staining strongly for EBNA2 but staining weakly or not at all for LMP1

(3) relatively large and blastic cells, even resembling (mononuclear variants of) ReedSternberg cells, showing expression of LMP1 but staining only weakly or not at all for EBNA2 (EBV latency type II expression pattern)

(4) neoplastic cells of intermediate size, expressing varying amounts of both EBNA2 and LMP1, indicative of an EBV latency type III expression pattern. 


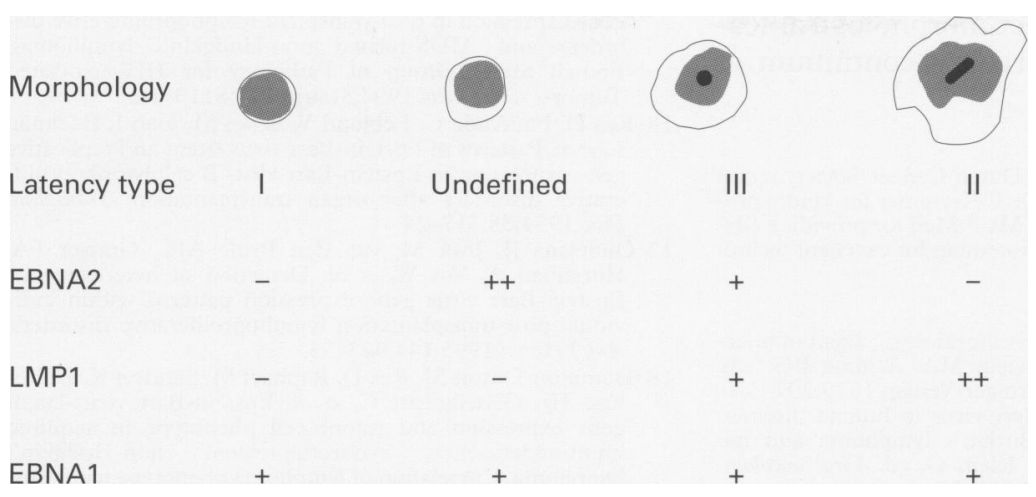

Figure 6 Schematic representation of relative EBNA1, EBNA2, and LMP1 expression levels in post-transplantation lymphoproliferative disorders and AIDS related lymphomas in relation to cell morphology. Relatively small tumour cells express high amounts of EBNA2 but no LMP1. It is tempting to assume that EBNA2 has upregulated the expression of LMP1 in the subsequent, more blastic phenotype. In the large blasts, which resemble mononuclear variants of Reed-Sternberg cells, high amounts of LMP1 are present, whereas EBNA2 is no longer expressed. EBNA1 is expressed in all phenotypes.

In the AIDS related lymphomas similar EBV expression patterns were observed, although the LMP1 positive, EBNA2 negative cells were not as large and blastic as in the posttransplantation lymphoproliferative disorder. Moreover, these four expression patterns were also detected in the infectious mononucleosis biopsy. Although the proportions of the four different phenotypes varied in the different clinical samples, the small EBNA2 positive, LMP1 negative cells, and the cells expressing both EBNA2 and LMP1 (latency type III) were most often observed in the three disorders studied.

\section{Discussion}

In lymphomas of immunocompromised patients, cells expressing immunogenic proteins, such as EBNA2 during latency type III, are not eradicated owing to the lack of a host immune response. Therefore, it is likely that all possible EBV expression patterns can be detected in these lymphomas. Indeed, in the present study using the most sensitive monoclonal antibodies available to date (R3 and 3E9 for EBNA2, S12 for LMP1), all possible combinations of EBNA2 and LMP1 expression including latency type III, were observed in correlation with certain morphological features of cells: small tumour cells, either EBNA1+/EBNA2-/ LMP1- (latency type I) or EBNA1+/ EBNA2+/LMP1 - (unknown pattern); cells of intermediate size staining positive for both EBNA2 and LMP1 (latency type III); larger, more blastic, and in post-transplantation lymphoproliferative disorders, even ReedSternberg-like cells expressing high amounts of LMP1 but no or little EBNA2 (latency type II-like). The expression of LMP1 in larger, more blastic cells in post-transplantation lymphoproliferative disorders and AIDS related lymphomas is in agreement with previous studies. ${ }^{15161823}$

LMP1 positive, EBNA2 negative posttransplantation lymphoproliferative disorders and AIDS related lymphomas have been observed in previous studies, ${ }^{16}{ }^{18}$ perhaps because the anti-EBNA2 monoclonal antibodies used then were not sensitive enough. ${ }^{16}{ }^{18}$ Alter- natively, EBNA2 transcriptional activation may not always be the cause of LMP1 expression. ${ }^{18}$

In the present study, using highly sensitive anti-EBNA2 and LMP1 monoclonal antibodies, we show that latency type III does exist at the single cell level in lymphomas of immunocompromised patients, a finding which has not been reported previously. These results are only found using the highly sensitive R3 and 3E9 antibodies, which indicates that in cells showing a latency type III pattern, EBNA2 is expressed at a very low concentration. In fact, latency type III cells seem to represent an intermediate between the EBNA2+/LMP1and the EBNA2-/LMP1+ cells, both when EBV expression and morphological features are considered. These results suggest that in lymphomas of immunocompromised patients, EBV infected cells are subject to a process in which the latent EBV gene expression alters gradually, along with changes in morphological features.

Also, the heterogeneous EBV expression in the lymphomas of immunocompromised patients revealed an interesting EBV expression pattern which could not be categorised as one of the "classic" latency types: relatively small tumour cells that express EBNA2 but no LMP1. This is in agreement with a previous study in which, using the less sensitive PE2 monoclonal antibody, a similar phenotype was observed in post-transplantation lymphoproliferative disorders. ${ }^{17}$ Based upon the expression of the BZLF1 lytical activator in a proportion of these smaller tumour cells, it was hypothesised that these cells are tending towards a lytical EBV infection. Alternatively, this phenotype could reflect an intermediate between latency types I and III, which is a subject for future investigation.

Based on the combination of the transactivating properties of EBNA2, ${ }^{21}$ the switches of EBV infected cells from one latency type to another as observed in vitro, ${ }^{22}$ and the changes in morphological features observed in the present study, it is tempting to speculate that lymphoma cells in immunocompromised patients can switch from one phenotype-the smaller, EBNA2+/LMP1 - tumour cells-via an intermediate phenotype with an EBV latency III expression pattern to the ReedSternberg-like phenotype expressing EBV latency type II. A schematic representation of this hypothesis is given in fig 6. Alternatively, different EBV expression patterns could reflect different phases in the cell cycle.

In conclusion, this study has shown that EBV latency type III at the single cell level does exist in a subpopulation of cells in posttransplantation lymphoproliferative disorders and AIDS related lymphomas when using the sensitive EBNA2 specific monoclonal antibodies R3 and 3E9. Therefore, these antibodies are highly recommended for the detection of EBNA2 expression at the protein level. Moreover, latency type III may represent a transitional stage between other EBV latency types in lymphomas of immunocompromised patients. This is indicated by the fact that the major classic latency types I, II, and III, which 
correlate to clearly distinct morphological features, appear to be a part of a continuum of EBV latency patterns.

This study was supported by the Dutch Cancer Society, grant VU 94-947. The authors thank Dr E Kremmer for kindly providing rat monoclonal antibodies, Ms P Meij for providing SF9 cells, and Mr W Vos and Mrs A Horstman for excellent technical assistance.

1 Henle G, Henle W. The virus as the etiologic agent of infectious mononucleosis. In: Epstein MA, Achong BG, eds. Epstein-Barr virus. Berlin: Springer-Verlag, 1979:297-320.

2 de-The G. Role of Epstein-Barr virus in human diseases: Infectious mononucleosis, Burkitt's lymphoma and nasopharyngeal carcinoma. In: Klein G, ed. Viral oncology. New York: Raven Press, 1980:769-97.

3 Liebowitz D, Kieff E. Epstein-Barr virus. In: Roizman B, Whitley RJ, Lopez C, eds. The human herpesviruses. New York: Raven Press, 1993:107-30.

4 Jones JF, Shurin S, Abramowsky C, Tubbs RR, Sciotto CG, Wahl R, et al. T-cell lymphomas containing Epstein-Barr viral DNA in patients with chronic Epstein-Barr virus infections. $N$ Engl f Med 1988;318:733-41.

5 De Bruin PC, Jiwa M, Oudejans JJ, Van der Valk P, Van Heerde P, Sabourin JC, et al. Presence of Epstein-Barr virus in extranodal T-cell lymphomas: differences in relation to site. Blood 1994;83:1612-18.

6 Kanavaros P, Briere J, Lescs MC, Gaulard P. Epstein-Barr virus in non-Hodgkin's lymphomas of the upper respiravirus in non-Hodgkin's lymphomas of the upper respira-
tory tract: association with sinonasal localization and tory tract: association with sinonasal localization and

7 Purtilo DT, Sakamoto K, Saemundsen AK. Documentation of Epstein-Barr virus infection in immunodeficient patients with life threatening lymphoproliferative disease by clinical, virological and immunopathological studies. Cancer Res 1981;41:4226.

8 Rowe M, Lear AL, Croom-Carter D, Davies AH, Rickinson AB. Three pathways of Epstein-Barr virus gene activation from EBNA1-positive latency in B lymphocytes. 7 Virol 1992;66:122-31.

9 Rowe M, Rowe DT, Gregory CD, Young LS, Farrell PJ, Rupani $\mathrm{H}$, et al. Differences in B cell growth phenotype reflect novel patterns of Epstein-Barr virus latent gene reflect novel patterns of Epstein-Barr virus latent gene
expression in Burkitt's lymphoma cells. EMBO $¥ 1987 ; 6$ : 2743-51.

10 Deacon EM, Pallesen G, Nieboditek G, Crocker J, Brooks $\mathrm{L}$, Rickinson AB, et al. Epstein-Barr virus and Hodgkin's disease: transcriptional analysis of virus latency in the malignant cells. $\mathcal{F}$ Exp Med 1993;177:339-49.

11 Chen C, Sadler RH, Walling DM, Su IH, Hsieh H, Raab Traub N. Epstein-Barr virus (EBV) gene expression in EBV-positive peripheral T-cell lymphomas. $\mathcal{F}$ Virol 1993;67: 6303-8.

12 Speck SH, Strominger JL. Transcription of Epstein-Barr virus in latently infected growth transfromed lymphocytes. Adv Virol Oncol 1989;8:133-50.

13 Gratama JW, Zutter MM, Minarovits J, Oosterveer MA, Thomas ED, Klein G, et al. Expression of Epstein-Barr virus-encoded growth-transformation-associated proteins in lymphoproliferations of bone-marrow transplant recipients. Int $\mathcal{f}$ Cancer 1991;47:188-92.

14 Oudejans JJ, Van den Brule AJC, Jiwa NM, de Bruin PC, Ossenkoppele GJ, van der Valk P, et al. BHRF1, the Epstein-Barr virus (EBV) homologue of the bcl-2 (proto)oncogene, is transcribed in EBV associated B-cell lymphomas and in reactive lymphocytes. Blood 1995;86:1893-902.

15 Rea D, Delecluse HJ, Hamilton-Dutoit SJ, Marelle L, Joab I, Edelman L, et al. Epstein-Barr virus latent and replicative gene expression in post-transplant lymphoproliferative disorders and AIDS-related non-Hodgkin's lymphomas. French Study Group of Pathology for HIV-associated Tumors. Ann Oncol 1994;5(suppl 1):S113-16.

16 Rea D, Fourcade C, Leblond V, Rowe M, Joab I, Edelman $\mathrm{L}$, et al. Patterns of Epstein-Barr virus latent and replicative gene expression in Epstein-Barr virus B cell lymphoproliferative disorders after organ transplantation. Transplant Proc 1994;58:317-24.

17 Oudejans JJ, Jiwa M, van den Brule AJC, Grasser FA, Horstman A, Vos W, et al. Detection of heterogeneous Epstein-Barr virus gene expression patterns within individual post-transplantation lymphoproliferative disorders. Am $\mathcal{7}$ Pathol 1995;147:923-33.

18 Hamilton-Dutoit SJ, Rea D, Raphael M, Sandvej K, Delecluse HJ, Gisselbrecht $\mathrm{C}$, et al. Epstein-Barr virus-latent gene expression and tumor cell phenotype in acquired immunodeficiency syndrome-related non-Hodgkin's lymphoma. Correlation of lymphoma phenotype with three distinct patterns of viral latency. Am f Pathol 1993;143: 1072-85.

19 Carbone A, Dolcetti R, Gloghini A, Maestro R, Vaccher E, di Luca D, et al. Immunophenotypic and molecular analyses of acquired immune deficiency syndrome-related and Epstein-Barr virus associated lymphomas. Hum Pathol Epstein-Barr virus
1996;27:133-46.

20 Pallesen G, Hamilton-Dutoit SJ, Rowe M, Lisse I, Ralfkiaer E, Sandvej K, et al. Expression of Epstein-Barr virus replicative proteins in AIDS-related non-Hodgkin's lymphoma cells. F Pathol 1991;165:289-99.

21 Alfieri C, Birkenbach M, Kieff E. Early events in Epstein-Barr virus infection of human B lymphocytes. Virology 1991;181:595-608.

22 Kerr BM, Lear AL, Rowe M. Three transcriptionally distinct forms of Epstein-Barr virus latency in somatic cell hybrids: cell phenotype dependence of promoter usage. Virology 1992;187:189-201.

23 Chetty R, Biddolph SC, Kaklamanis L, Cary N, Stewart S, Giatromanolaki A, et al. EBV latent membrane protein (LMP-1) and bcl-2 protein expression in Reed-Sternberglike cells in post-transplant lymphoproliferative disorders. Histopathology 1996;28:257-60.

24 Chetty R, Biddolph FRCPAS, Kaklamanis L, Kremmer E, Cary N, Stewart S, et al. Immunohistochemical demonstration of Epstein-Barr virus nuclear antigens 1 and 2 in posttransplant lymphoproliferative disorders. Appl Immunohistochem 1996;4:102-5.

25 Kremmer E, Kranz BR, Hille A, Klein K, Eulitz M, Hoffmann-Fezer $\mathrm{G}$, et al. Rat monoclonal antibodies differentiating between the Epstein-Barr virus nuclear antigens 2A (EBNA2A) and 2B (EBNA2B). Virology 1995; 208:336-42.

26 Jiwa NM, Kanavaros $P$, De Bruin PC, van der Valk $P$, Horstman A, Vos W, et al. Presence of Epstein-Barr virus harbouring small and intermediate-sized cells in Hodgkin's disease. Is there a relationship with Reed-Sternberg cells? $\mathcal{f}$ Pathol 1993;170:129-36.

27 Sample J, Young L, Martin B, Chatman T, Rickinson A, Kieff E. Epstein-Barr virus types 1 and 2 differ in their EBNA-3A, EBNA-3B and EBNA-3C genes. $\mathcal{F}$ Virol 1990; 64:4084-92.

28 Grasser FA, Murray PG, Kremmer E, Klein K, Remberger K, Feiden W, et al. Monoclonal antibodies directed against the Feiden W, et al. Monoclonal antibodies directed against the
Epstein-Barr virus-encoded nuclear antigen 1 (EBNA1): immunohistologic detection of EBNA1 in the malignant cells of Hodgkin's disease. Blood 1994;84:3792-8.

29 Jiwa NM, Oudejans JJ, Dukers DF, Vos W, Horstman A, van der Valk P, et al. Immunohistochemical demonstration of different latent membrane protein-1 epitopes of EpsteinBarr virus in lymphoproliferative diseases. $\mathcal{f}$ Clin Pathol 1995;48:438-42. 